\title{
Reviewing the Purpose of Education and Challenges Faced in Implementing Sound Pedagogical Practices in the Presence of Emerging Evidence from Neuroscience
}

\author{
Chandana Watagodakumbura, ${ }^{1, *}$ \\ ${ }^{1}$ Faculty of Information Technology, Monash University, Melbourne, Australia \\ *Correspondence: Faculty of Information Technology, Monash University, 3/4 Delany Lane, Craigieburn, Vic 3064, \\ Australia. Tel: 61-40-139-1618. E-mail: chandana.watagodakumbura@monash.edu
}

Received: September 30, 2015

Accepted: October 21, 2015 Online Published: November 22, 2015

doi:10.5430/wje.v5n6p23

URL: http://dx.doi.org/10.5430/wje.v5n6p23

\begin{abstract}
The field of neuroscience has been evolving constantly and at a rapid pace in the recent past. Consequently, neuroscientists have put forth a wealth of knowledge in relation learning and education in general. In this context, how can we as educators benefit from the emerging evidence from neuroscience so that we can take a significant step forward in improving our pedagogical practices? We can take a deeper and reflective look at our existing pedagogical knowledge-base and engage in implementing necessary changes in such a way that we can guide our learners to reach their full potential. By reaching full potential, we mean enhancing creativity and wisdom in our day to day life operations, thus developing more empathic and content personalities devoid of psychological disorders. In the presence of emerging evidence, we can be better organised and take more educated decisions in planning our curricular, assessment and content delivery methods to achieve enhanced learning. We certainly face some challenges, especially in changing from some practices that were used widely and for a prolonged time. However, taking this courageous step forward would help us to be more sustainable in our educational systems as well as society at large. In this regard, this paper discusses some emerging neuroscience-based concepts relevant to learning and education in general, the significance of these concepts and some suggestions on how they can be incorporated in our pedagogical practices.
\end{abstract}

Keywords: Education; Learning; Neuroscience; Consciousness; Creativity; Wisdom; Brain structure; Episodic and semantic memory; Associative recall and recognition tests

\section{Introduction}

This paper begins with a section that introduces neuroscience concepts related to learning and education. In the latter part, elaborations are made on how more educated decisions can be made on our pedagogical practices using neuroscience-based evidence. How we can understand creativity and wisdom through facts from neuroscience is presented first. Significance of applying the theory of multiple intelligences is explained then. We move on to get a better grasp of how giftedness and overexcitabilities of some individuals support better learning before presenting the popular Kolb's experiential learning cycle and Bloom's taxonomy through the eyes of neuroscience. The differences between the two learning styles of auditory-sequential and visual-spatial are presented more deeply next. Why we should avoid machine-type learning used for routine operations as human beings learn by continuously expanding their neural networks is elaborated. Finally, why high-level concepts need emphasis ahead of specific details in any teaching-learning environment is explained from the evidence of neuroscience deeply.

\section{Introduction to Neuroscience-Based Concepts that Relate to Learning and Education}

\subsection{Basic Structure of the Human Brain (Baars \& Gage, 2010)}

Mainly there are 3 layers of the brain, from bottom to top: the reptilian brain, mammalian brain and neocortex (MacLean, 1967). The reptilian brain is the oldest layer of the brain; it is composed of the brain stem, the structures that dominate in the brains of snakes and lizards. This part of the brain controls survival activities such as breathing, hart rate and balance. The mammalian brain is layered over the reptilian brain and consists of a system of brain parts 
called the limbic system. The constituents of the limbic system include amygdala, hippocampus and hypothalamus. The limbic system plays a major role in human emotions. The $3^{\text {rd }}$ layer of the brain is the neocortex or primate brain which is the most recent addition to our brain. It consists of wrinkled covering of cerebral hemispheres - the left and right. The neocortex plays a major role in cognitive, linguistic, motor, sensory and social abilities. It gives a considerable flexibility in creativity in adapting to changing environments. The neocortex is densely interconnected with the limbic system and controls the expression of emotions.

The neocortex has 4 major lobes, namely, the frontal lobe, parietal lobe, temporal lobe and occipital lobe. One significant feature of the brain structure is brain localisation. That is, the brain is composed of a large number of functionally specialised regions (Luria, 1976; Geschwind, 1979; Edelman and Mountcastle, 1978). There are about 100 Brodman areas, so to speak, now recognised in the neocortex. The 4 lobes of the neocortex and their processes are intricately intertwined with each other. Further, the neocortex, which is vital for cognitive functions, interacts constantly with major so called satellite organs such as the thalamus, basal ganglia, cerebellum, hippocampus and limbic regions.

Interestingly, the right and left cerebral hemispheres of the neocortex have differentiated functions. The left hemisphere is more specialised in performing verbal and linguistic, mathematical, sequential and analytical functions while the right hemisphere is more inclined to perform non-verbal, spatial, geometrical, musical and synthesis functions (Silverman, 1998, 2002). The 2 cerebral hemispheres are connected together by the largest fibre bundle in the brain- corpus callosum.

It is of special interest to know that frontal lobes are referred to as the organ of civilisation. The role the frontal lobes play in cognition is uniquely human and without their development civilisation could never have arisen (Fuster, 1997; Goldberg, 2001; Ingvar, 1985; Luria, 1966). They are crucial for all higher-order purposeful behaviour such as identifying the objective, projecting the goal, forging plans to reach it, organising the means by which such plans can be carried out and monitoring and judging the consequences. Further, frontal parts of the brain become active when resolving conflicting conditions. A correlation has also been identified between frontal activation and longer reaction time and sense of subjective effort. In summary, the frontal lobe, or more specifically the pre-frontal cortex (PFC), is used for human activities such as language, thought and executive control of higher-order processes and connect directly with every distinct functional unit of the brain (Nauta, 1972). This connectivity allows PFC to coordinate and integrate the functions of other brain structures.

\subsection{Types of Memory (Baars \& Gage, 2010)}

Human memory (Squire, 2004, 2009) can be defined as a lasting representation that is reflected in thought, experience, and/or behaviour. It can be divided in to 2 main types: explicit and implicit. Explicit memory refers to the memory with conscious awareness and the individual can declare its existence and comment on its content either verbally or non-verbally (Cohen \& Squire, 1980; Ryle, 1949). Consequently, such memories are known as declarative memories. On the other hand, implicit memory is not accompanied by conscious awareness that one has a memory; the existence of implicit memory is inferred only from the effects it has on behaviour. Further, implicit memories may be retrieved without an intention to remember and accessed commonly by priming tasks (Banaji \& Greenwald, 1995; Curran, 2001; Knowlton et al, 1996)...

Explicit or declarative memory can be further divided into 2 types: episodic (autobiographical) memory and semantic memory (Tulving, 1972; 1985). Episodic memory refers to memories that have a specific source in time, space and life circumstances. In contrast, semantic memories involve facts (or high-level concepts and generalisations) about us, the world, and other knowledge that we share within a community and are independent of the spatial and temporal context in which they were acquired. Further, episodic memories are remembered consciously and susceptible to forgetting while semantic memories give a feeling of knowing rather than a fully conscious recollection and less susceptible to forgetting. Initially memories are episodic and context dependent and over time they are transformed into semantic memories (Penfield and Milner, 1958).

Another categorisation of human memory is the division into the 2 types referred to as working memory (Baddeley, 2000; Baddeley and Hitch, 1974; Cowan et al, 2005) and long-term memory (Dudai, 2004; LeDoux, 1996; Lees et al, 2000; McGaugh, 2000). Working memory is defined as the set of mental processes holding limited information in a temporarily accessible state in service of cognition. Prefrontal cortex (PFC) seems to play an important role in working memory processes and temporal and prefrontal regions of the cortex appear involve in working storage. Long-term memory, on the other hand can be large quantities of information stored in a more permanent or longer duration basis. The neocortex is believed to encode long-term memories by altering synaptic connections between billions of neurons. There are trillions of such synapses in the cortex and its satellite organs. Memories are believed 
to be unstable and vulnerable to interference in the early hours after they are formed, and after about a day, they appear to be consolidated or made more enduring (Hobson and Stickgold, 1995). This process of consolidation is thought to require protein synthesis and sleep and dreaming seem to support this process.

\subsection{Types of Learning from the Viewpoint of Neuroscience (Baars \& Gage, 2010)}

Learning can be defined as the acquisition of lasting representations that involve a wide range of brain areas and activities. Very often, the unstated goal of learning is to turn explicit problem solving into the implicit kind. Similar to the way we discussed about explicit and implicit memories, learning can also be explicit or implicit. Explicit or declarative learning involves conscious learning while implicit (unconscious) learning (Berry and Dienes, 1993; Cleeremans, 1993) results as a side effect of conscious input. That is, even for implicit learning, conscious events guide the learning process. But there is no exclusively conscious learning as both, conscious and unconscious, processes always go together. In a complete learning cycle, 3 phases can be identified: learning, retention and retrieval. Retention is generally viewed as unconscious, although it is shaped by conscious experiences. Explicit learning generally occurs when we pay attention to new information so that it becomes conscious. The brain begins learning as soon as it is placed in any novel environment. Simple novelty is enough to trigger attention and learning, including significant evoked potentials that sweep through the entire cortex. As soon as we experience or understand the new information with enough clarity, our brains are able to store it (Seitz \& Watanabe, 2005)... Sometime it may require repeated attention new or difficult information in order for us to get a sense of clarity. Any new material may seem vague or hard to understand at first; however, when we spend time thinking about it or paying attention to it, a clearer sense of meaning tends to appear.

Brain takes more time to solve novel problems and voluntary actions become automatic with practice. As they do so, we tend to lose executive control over them. Cortical activity reduces when predictable voluntary action is practiced to the point of automaticity (Chein and Schneider, 2005; Coulthard et al, 2008; Langer and Imber, 1979; Raaijmakers and Shiffrin, 1992; Schneider, 2009; Shiffrin and Schneider, 1977). Once even very complex processes are learned, they seem to require less cortical activity.

Most of our learning is identified to be incidental, meaning that it occurs as a result of paying attention and becoming conscious of. That is, we do not deliberately memorise things all the time; memorising is only one way to make learning happen.

With our current practices, academic learning is mostly explicit with teachers pointing out the things to be learned and students doing their best to memorise them. However, most ordinary human learning is implicit. For example, social habits and language are mostly leant implicitly. Looking from another perspective, most knowledge is tacit knowledge and most learning takes place implicitly before it can be stated explicitly. Further, academic exams usually test associative recall (What is the capital of Australia?) rather than recognition tests. Associative recall tests give much lower estimates for accurate memories than recognition tests. That is, in associative recall, we expect more exact and specific answers than in recognition tests. Interestingly, these exact and specific answers are the ones that are likely to be forgotten soon (Tulving, 1972; 1985).

In the event of some emotional stimuli, there is evidence that unconscious learning takes place. That is, this gives much stronger evidence for implicit learning, in which some inferential process takes conscious input and encodes unconscious results. In other words, emotional learning results in implicit emotional memory that retains classically conditioned emotional relationships that cannot be voluntarily recollected or reported (Phelps and LeDoux, 2005; Panksepp, 1998). Psychological evidence shows that moderate levels of emotional arousal at the time of an event lead to better retention of explicit memories (Sylwester, 1998). That is, explicit memories are better consolidated by the reception of emotional stimuli by the amygdala.

Hebbian learning, named after neuropsychologist Donald Hebb, is summarised to "neurons that fire together wire together" (Hebb, 1949). It indicates that the more frequent certain synaptic connections are made the more likely they are to form lasting neural networks. In other words, synaptic connections that are rarely used will eventually die out (Diamond, 1996, 2001). This is a very simple idea on how we can explain the way learning takes place. In fact, it is observed that forming new synaptic connections or synaptogenesis (Huttenlocher et al, 1982; Huttenlocher, 1994) takes place throughout one's lifespan, enabling a lifelong learning process. In other words, cortical plasticity lasts throughout the lifespan of a human being. However, in a changing, dynamic world, unlearning also has an important role to play. That is, we will have to let misconceptions or inaccurate knowledge to die out from our neural system. A similar concept known as neural Darwinism - survival of the fittest cells and synapses- is presented by Edelman (1989). In that, human brains are identified to be selectionist rather than being instructionist, meaning that synaptic connections can grow by selecting new connections, not merely being restricted by an existing limited set of 
instructions as that happens in computers. In other words, human brains can be creative by learning new knowledge in the form of new synaptic connections that did not exist before.

\subsection{Consciousness from the Viewpoint of Neuroscience (Baars \& Gage, 2010)}

Scientists have confirmed that consciousness can be defined and studied scientifically, contrary to the beliefs held previously (Baars et al, 2003; Edelman, 1989, 1993, 2005, 2007; Edelman \& Tononi, 2001; Koch, 1996; Palmer, 1999; Tononi \& Edelman, 1998; Tulving, 2002). Consciousness results from neuronal interaction between thalamocortical systems; the neocortex is the main organ involved in it. The evolution of consciousness is understood to be the highest expression of the developed brain that parallels the evolution of the prefrontal cortex (PFC). Synonyms used for consciousness are awareness, explicit cognition and focal attention. Consciousness can be identified mainly in two levels - primary and higher-order consciousness. The former is concerned with perceptual world while the latter is related to abstractions and thought. Further consciousness involves with a range of contents: sensory perception, visual imagery, emotional feelings, inner speech, abstract concepts and action related ideas indicating the involvement of a number of brain regions, through an integrative view. Of special interest is the theory developed by Giulio Tononi in the name of Integrated Theory of Consciousness (Bulduzzi \& Tononi, 2008; Koch and Tononi, 2008; Tononi, 2008). It provides a new way to study consciousness using a rigorous scientific approach. Integrated theory of consciousness is a framework that is built on the notion that consciousness is a consequence of systems that have both a large amount of differentiated information that is also highly integrated. To summarise the idea, a computer may have a large quantity of memory (say 16 GB), but since these memory pieces are not integrated, computers do not have consciousness. Scientists have also been able to quantify the level of consciousness with a measure called neural complexity (C) (Edelman \& Tononi, 2001). High values of C characterise conscious events and reflects the extent to which the dynamics of a neural system are both integrated and differentiated. Consciousness in humans can also be understood with the cognitive architecture known as Global Workspace Theory (GWT) (Baars, 1988, 2002). GWT proposes that momentarily dominant information is widely distributed in the brain. That is, the nervous system can be viewed as a massive distributed set of special-purpose networks. Consequently, coordination, control, and novel problem solving could take place by way of central information exchange. Conscious involvement of brain resources is particularly useful when novel information needs to be combined and integrated.

\subsection{Intelligence from the Viewpoint of Neuroscience (Baars \& Gage, 2010)}

Evolution of intelligence is viewed as an increase in the ability to apply specialised functions from different regions of the brain to life situations (Rozin, 1976). Further, during human lifetime, specialised functions can become available for new adaptive purposes. That is, more specialised neural networks are differentiated during the life time and these differentiated networks are integrated to adapt to new situations. Consequently, we see some overlapping concepts in the inferential abstractions of consciousness and intelligence. Further, studies on intelligence have revealed some notable findings. That is, high intelligence quotient (IQ) was associated with thinner cortex, especially in frontal temporal lobe areas, in early childhood. But, by late childhood, the opposite pattern was found, with high IQ associated with thicker cortex (Shaw et al, 2006). The researchers concluded that differences in grey matter density did not lead to children with superior intellectual abilities; rather they suggested that the dynamic properties of development of the cortex corresponded to level of intelligence, perhaps enabling the child to extract more information from his environment.

\subsection{Attention from the Viewpoint of Neuroscience (Baars \& Gage, 2010)}

The word attention seems to imply the ability to direct cognitive resources to some event. It has a kind of pointing or directive sense. Selective attention implies a choice among a number of possible events. Consciousness seems to be the experience of an event after it has been selected by paying attention. We can decide voluntarily what to become conscious of or the selection can also be automatic if stimuli are intense, dynamic or biologically or personally important. In the real world, voluntary and automatic attentions are generally mixed. In summary, attention is defined as the ability to select information for cognitive purposes. This selection may be shaped by emotion (Zull, 2002), motivation and salience and is at least partly under executive control. The term binocular rivalry is used to describe the process of selective attention in neuroscience (Logothetis, 1998; Tong et al, 1998). When 2 items are looked at the same time using one eye on each item using a pair of binoculars, at an instance of time we can only see one item properly or consciously. In other words, we cannot concentrate well on 2 things at the same time even though we see them both simultaneously. That is, when a person is given a task that requires in-depth, meaningful analysis of the material, memory under divided attention is much worse than memory under full attention. Deeper processing requires time to complete and divided attention limits the time allotted to encoding (Anderson et al, 2000; 
Fletcher et al, 1995). In learning, what we generally do is just pay attention to new material, even if it seems hard to understand. The biggest challenge is to pay continued attention to new and difficult information and to be patient enough to allow our brains to do wonder, ask questions, and ultimately comprehend any new material (Seitz \& Watanabe, 2005).

\subsection{Automaticity from the Viewpoint of Neuroscience (Baars \& Gage, 2010)}

In general, the more predictable a sensorimotor skill becomes, the less of it will become conscious. The fading of conscious access to habitual skills is commonly called 'automaticity' and it goes along with a loss of precise voluntary control over habitual details (Chein and Schneider, 2005; Coulthard et al, 2008; Langer and Imber, 1979; Raaijmakers and Shiffrin, 1992; Schneider, 2009; Shiffrin and Schneider, 1977). Repetitive events tend to fade from consciousness unless they have special significance. That is, voluntary actions we are conscious with become automatic with practice. As they do so, we tend to lose executive control over them. In other words, effortful tasks show a wider spread of brain activity; the brain takes more time to solve novel problems and switching from one task to another seems to require additional mental resources beyond those involved in routine and automatic actions. The level of activity in cortex (at least) drops with practice and automaticity. It seems to indicate the recruitment of neuronal resources that are needed to work together to perform a task that is new or unpredictable.

\subsection{Auditory and Visual Systems in Relation to Time (Baars \& Gage, 2010)}

Time is a critical aspect of auditory processing; auditory systems differ from the visual system in that all sound processing occurs over time. That is nothing stands still, unlike in the visual system that can have simultaneous or parallel processing. Further, the auditory cortex is activated during speech production tasks as well as during the perception of speech. That is, it indicates a link between speech perception and production.

Of special interest is how musical processing takes place in the brain. Music has complex phrase structures and its perception involves the mapping of sound onto meaning and emotion. The perception of features in music involves many stages of processing within the auditory system as well as across brain regions (Peretz \& Zatorre, 2005).

\subsection{Goals of Education from the Viewpoint of Neuroscience (Baars \& Gage, 2010)}

Very often, the unstated goal of learning is to turn explicit problem solving into the implicit kind. Explicit problem solving has clear conscious goals and clearly defined steps, greater executive control, higher mental workload, wider recruitment of cortical regions (Unterrainer \& Owen, 2006). Implicit problem solving is, however, more common and will become more proficient, implicit (unconscious) and automatic with practice (Bowers et al, 1990; James, 1890; Metcalfe, 1986; Yzerbyt et al, 1998). It uses less executive control, has less cortical involvement and is more dependent on long-term memory and highly practiced routines.

As a part of goals of education, individuals also need to become better decision makers through education. In schools or colleges, we are usually given a problem or question and we must find or write the correct answer. Usually only one correct answer exists to these questions or problems. For example, balancing a check book and remembering the capital city of a country are similar tasks. By finding the correct solution, we engage in veridical decision-making. However, apart from high school exams, college tests and factual and computational trivia, most decisions we make in our everyday lives do not have intrinsically correct solutions. That is, the decisions we make are not always objective, rather they are, in most cases, subjective. What career path to make, what location to visit in the vacation are some such example decisions we make in ambiguous situations. By making a decision or choice, we engage in adaptive decision-making. Further, our best neural system performance is not for the exact symbol sequences that conventional computers handle so well. Rather, our brains are exceptionally good at dealing with complex, ill-defined, and novel challenges, the kinds that people have to deal with in the real world. That is, humans are exceptionally flexible in adapting to new conditions. The choices we make are not inherent in the situations at hand. There are complex interplay between the properties of the situations and our own individual properties, aspirations, doubts, and histories. The prefrontal cortex (PFC) is central to such decision-making or evaluation. Finding solutions for deterministic situations often is accomplished algorithmically or following a number of steps routinely. These tasks are increasingly delegated to various devices such as calculators, computers and the like. However, making judgments, in the absence of inherently correct solutions, remain, at least for now, a uniquely human territory. Thus, through education an individual must develop the capacity to have the flexibility to adopt different perspectives on the same situation at different times. The organism must be able to disambiguate the same situation in multiple different ways and to have the capacity to switch between them at will. Frontal lobes of the brain hemispheres play an important role in dealing with these ambiguous situations.

It appears that goals of and approaches to science education have shifted recently. Science usually works from a third 
person perspective. This means that researchers adopt an objective point of view, seeing all evidence as a physical object. Even human beings are seen as objects. Recently, scientists interested in consciousness have begun arguing for an additional way of conducting and approaching science that appreciates and accepts data gathered from first person perspective, i.e. phenomenological data from introspection or self-report. In second person perspective, the other person is viewed as a subject rather than an object, as someone who has mental states (Baron-Cohen, 1995; Frith and Frith, 1999).

\section{Understanding Pedagogical and Learning Related Concepts and Practices More Deeply in the Presence of Evidence from Neuroscience}

\subsection{Understanding Creativity/Wisdom}

Creativity in human beings is associated with the ability to produce or form new ideas or inferences. Wisdom is understood to be an advanced form of creativity in which useful inferences are formed essentially using knowledge from multiple domains (Claxton, 2008). Creativity and wisdom are essentially human qualities which are not clearly present in other species or machines. From an educational point of view, we earnestly want our learners to develop creativity and wisdom. From the viewpoint of neuroscience, information or knowledge is represented and stored in the form of neural networks (Kuhn, 1962). Consequently, creativity can be understood as creating neural networks within somewhat a limited number of brain functional areas while an act of wisdom would result when a highly integrated neural network is formed across a larger number of brain regions. Wisdom is clearly a concept that goes hand-in-hand with consciousness defined in neuroscience (see section 2.4 for the definition). The degree of consciousness indicates how well information stored in the brain is differentiated in each individual area and, at the same time, integrated across those multiple areas (Bulduzzi \& Tononi, 2008; Koch \& Tononi, 2008; Tononi, 2008). As a result, we can say that an individual who demonstrates a very high level of wisdom is a person with high level of consciousness. In other words, since the evolution of consciousness is regarded as the highest expression of developed brain (see section 2.4), an individual can be humanistically and biologically at his/her best when a very high level of consciousness or wisdom is achieved. Such highly evolved persons, at the highest level, were referred to as self-actualised individuals (Maslow, 1968, 1993) and at level 5, the highest level, of human development process (Dabrowski, 1970, 1977) in the literature. The challenge in our social and education systems is to identify ways in which we can improve creativity and wisdom in individuals and how we can recognise and utilise these high human abilities so that the society will benefit from them. In a contemporary society in which economic development is valued predominantly ahead of human development, what revolutionary changes do we need to make to encourage self-actualisation of human beings?

\subsection{Understanding the Theory of Multiple Intelligences}

The theory of multiple intelligences (Gardner, 2006) indicates that there are a number of basic human ability areas or intelligences, so to speak, as opposed to a single measure of ability or intelligence. The multiple intelligences Gardner presented were verbal-linguistic, logical-mathematical, visual-spatial, interpersonal, intrapersonal, musical and bodily-kinaesthetic. Interestingly, from the viewpoint of neuroscience, these intelligences are most likely to be associated with different functional areas of the brain (Luria, 1976; Geschwind, 1979; Edelman and Mountcastle, 1978). For example, broadly, verbal-linguistic ability is associated with left hemisphere while visual spatial ability is associated with the right hemisphere (Silverman, 1998, 2002). Wernicke's area in the left upper part of the temporal lobe is associated with receptive language or speech perception (Baars \& Gage, 2010; Friederici, 2002; Hickok and Poeppel, 2007). An important point to note here is that it is possible that an individual has some of the intelligences or capabilities and the associated functional areas developed better than the other areas. That is, we may have asynchronous developments across multiple intelligences or functional areas within an individual (Silverman, 2002; Webb et al, 2005). Using the definitions in neuroscience and the integrated theory of consciousness (see section 2.4); it indicates that only a limited number of functional areas may have been differentiated well. From an education viewpoint, the key point to understand is that all types of intelligences or capabilities mentioned above are highly important for the overall development of an individual, by enabling to raise the level of consciousness (see section 2.4 for definition); as a result, we should encourage and guide individuals to take part in activities that encourage the above mentioned holistic human development. Implementing these measures will require us, as educators, to identify strong and weak areas of development or intelligences within each individual systematically and put forth appropriate learning plans to improve on the lagging areas while relying on the stronger ones as pathways to achieve it. 


\subsection{Understanding Overexcitabilities/Gifted Characteristics}

The term "overexcitabilities" was coined in by Kazimierz Dabrowski to highlight the neural characteristics of highly sensitive individuals (Dabrowski, 1970, 1972, 1977). These individuals demonstrate certain over stimulations compared to others in the areas Dabrowski identified as intellectual, emotional, imaginational, psychomotor and sensual. The individuals characterised as gifted mostly demonstrate intellectual, emotional and imaginational overexcitabilities. As highlighted in section 2.5, an intellectual ability relates to a well differentiated functional area in the brain (Rozin, 1976) and high intelligence indicates the dynamic properties of the brain that helps the development of the cortex into a denser neural network (Shaw et al, 2006). When a higher number of intelligences or capabilities and related functional brain areas are differentiated and integrated at the same time, individuals develop denser neural networks that result in a higher level of consciousness (see the definition of consciousness in section 2.4). Further, the limbic system of the brain that plays an important role in human emotions is highly connected with neocortex (Zull, 2002) and emotions that mostly produce implicit memories through incidental learning also motivate individuals to learn (Baars \& Gage, 2010; Panksepp, 1998). Consequently, since gifted individuals demonstrate intellectual and emotional overexcitabilites (Dabrowski, 1970, 1972, 1977; Silverman, 2002, Webb et al, 2005), it suggests that they possess inherent capacities to develop denser neural networks across the whole neocortex by extracting large quantities of information from the environment, either explicitly or implicitly. That is, these individuals have the abilities to develop higher levels of consciousness (see section 2.4 for the definition and references). Thus, considering that most of our learning is implicit, we, as educators, have to pay special emphasis in the way how we recognise and assess gifted learners accurately and helping them to reach their full potential. Of special note is the challenges we face in identifying asynchronous as well as implicit development of gifted individuals (Eide \& Eide, 2004; Webb et al, 2005); it is more common that gifted individuals demonstrate high levels of visual-spatial abilities which are also right-hemispheric biased (Silverman, 1998, 2002). In a contemporary education system that relies heavily on valuing left-hemispheric features such as verbal-linguistic abilities, the challenge is to identify and recognise visual-spatial abilities as well as implicit learning or knowledge of gifted individuals. By taking into account the neurological differences of individuals in a teaching-learning environment, we address the issues related to what is referred to as neurodiversity (Armstrong, 2011).

\subsection{Understanding Kolb’s Experiential Learning Cycle}

Kolb's experiential learning cycle is widely used to describe a complete learning activity (Kolb, 1983). It has four stages, namely, concrete experience stage, reflective observation stage, abstract conceptualisation stage and active experimentation stage. From the viewpoint of neuroscience, the important point to understand is that, in Kolb's cycle, we encourage learners to use different functional areas of the brain, namely the sensory cortex, back integrative cortex, frontal lobes and motor cortex, to achieve complete learning (Zull, 2002). For example, concrete experiences such as observing and hearing are absorbed in the sensory cortices (visual and auditory) while active experiments can be performed by signalling the area of motor cortex. Of special note are the two stages reflective observation and abstract conceptualisation in which higher order learning such as synthesis and evaluation take place (Watagodakumbura, 2013). These stages essentially perform the integrative functions of the learning activity. The pre-frontal cortex in the frontal lobes plays a significant role in these integrative processes (Baars \& Gage, 2010; Fuster, 1997; Goldberg, 2001; Ingvar, 1985; Luria, 1966). It is important to note that the frontal lobes have played a major role in the evolution of human civilisation, and getting them essentially involved in the learning process direct us towards achieving higher-order learning. That is, they help learners to build widely integrated neural networks as part of their learning. Remember that enhancing consciousness, the highest expression of developed brain, in learners, which is also directly associated with human development to higher levels, essentially requires the above integrating functions from wider areas or domains of the brain (see section 2.4 for the definition of consciousness and references). Viewing from another direction, we get to understand that abstract conceptualisation stage of the Kolb's cycle that uses the frontal lobes plays the most important role in human learning as it is the stage in which human creativity and wisdom play a significant role.

\subsection{Understanding Bloom's Taxonomy/Surface and Deep Learning}

When Bloom's taxonomy (Biggs, 2003; Entwistle, 1998) is used for understanding the level of learning, evaluation and synthesis are the functions at the higher end or functions that involve higher-order learning. Knowledge and comprehension functions are at the lower end while application and analysis are at the middle level. From the viewpoint of neuroscience, synthesis is a process that we create new knowledge in which new neural networks are created, usually connecting multiple domain areas. By enabling integration of different parts of the neocortex or neural networks of knowledge, as that happens in enhancing consciousness (see section 2.4 for the definition), we 
can allow learners to engage in the process of synthesis at the highest level. Synthesis, in other words, is the process of making new inferences (Baars \& Gage, 2010) by linking neural networks together. Similarly, the process of evaluation can be achieved at the highest level by allowing learners to make a comparative judgement from the knowledge or information spread in different parts of the neocortex; remember here that we are comparing here different neural networks of knowledge (Kuhn, 1962), ideally from different domain areas. The functions at the lower or middle levels of the Bloom's taxonomy - knowledge, comprehension, application and analysis - may visibly lack the integration part of different brain functional areas. Thus, we get to an understanding that in high-order learning functions such as synthesis and evaluation, the most important process is the integration of knowledge from different brain functional or domain areas. Recall that, wisdom as a higher level of creativity that integrates knowledge from different domains (see section 3.1 for more details). Further, at a higher level of consciousness, neural networks across wider brain areas communicate together (see section 2.4 for definition and references). From another point of view, in deep learning or critical thinking (Paul and Elder, 2000), we make learners engage in higher-order learning activities such as synthesis and evaluation so that lasting memories are formed in contrast to surface or strategic learning in which short-term memory is the outcome. Put differently, knowledge, comprehension, application and analysis functions of the Bloom's Taxonomy should not be the ends of learning; instead they can be the means by which synthesis and evaluation functions are achieved or higher order learning is directed. Consequently, it is imperative that assessments tasks focus on the higher-end of the Bloom's spectrum.

\subsection{Differentiating Auditory-Sequential and Visual-Spatial Learning}

Auditory-sequential and visual-spatial learning types (Silverman, 1998, 2002) are differentiated mainly on the likelihood of using left or right hemispheric brains more predominantly. Auditory-sequential learners demonstrate strengths in auditory skills, relate well to time, prefer analytical and sequential operations, good in short-term memory and rote memorisation, comfortable with one right answer and able to overcome emotional setbacks quickly. On the other hand, visual- spatial learners have strengths in visual skills, relate well to space, learn concepts all at once and good in synthesis, have good long-term memory, dislike drill and repetition and demonstrate higher emotional and other sensitivities. Further, visual-spatial learners are more likely to be identified as gifted individuals and are usually introverts while auditory-sequential learners are usually extroverts. From the viewpoint of neuroscience, auditory systems differ from the visual system in that all sound processing occurs over time (see section 2.8 for details). This fact explains why auditory-sequential learners have a better sense of time and do well in sequential activities. Further, it is observed that auditory cortex is activated during speech perception as well as speech production. That infers that auditory-sequential learners are better in both listening as well as in speech. This inference explains why auditory-sequential learners are usually extroverts who are more active and fluent verbally while visual-spatial learners are introverts. It is worth noting that musical interests are of a special type of auditory skill that integrates more parts of brain mapping sound onto meaning and emotions (Peretz and Zatorre, 2005). Consequently, visual-spatial learners also could get involved in musical activities actively.

\subsection{Differentiating Machines, Human Brain and Learning}

Human brains are identified to be selectionist (Baars \& Gage, 2010; Edelman, 1989) in which new neural connections can always be created or grow by making new synaptic connections among a very large number of dendrites present. On the other hand, typical computers are said to be instructionist where a limited set of instructions or symbols are carried out to perform a limited set of tasks. Consequently, we say human brains are creative due to the fact that they can create theoretically an infinite number of neural networks or pieces of knowledge. Further, typical computer are better in operating sequentially or algorithmically in finding answers to problems where there are exact or predefined answers (Baars \& Gage, 2010; Beale and Jackson, 1990). Some examples would be to multiply two large numbers or balancing an account book. On the other hand, human brains are better suited for making a judgement or choice where there is no one correct answer. These answers can vary from person to person, context to context and time to time. Consequently, the same individual can make different decisions on the same problem at different stages of life. That is, human beings can learn/unlearn taking different perspectives into consideration. The prefrontal cortex (PFC), which is considered as an essential component of human civilisation, plays a very important role in such decision making or choices in ambiguous situations (Baars \& Gage, 2010; Fuster, 1997; Goldberg, 2001; Ingvar, 1985; Luria, 1966). It has been observed that when PFC is used for integrative decision making activity, the process is relatively slower or takes more time. Another related concept is automaticity in which involvement of cortical resources from various brain regions reduces significantly when a highly practiced activity is carried out (Chein and Schneider, 2005; Coulthard et al, 2008; Langer and Imber, 1979; Raaijmakers and Shiffrin, 1992; Schneider, 2009; Shiffrin and Schneider, 1977). These observations explain the reason why typical 
computers or machines are better in carrying out routine tasks much quicker than a decision making of novel task of a human being. One of the goals of education is to convert explicit problem solving to implicit type in which we may use less cortical resources. However, due to the plasticity nature of human brain (Scholz, Klein, Behrens \&Johansen-Berg, 2009; den Ouden, Friston, Daw, McIntosh \& Stephan, 2009), once a solution or activity is mastered to a level of automaticity, ideally, the individual need to shift the focus so as to concentrate or utilise cortical resources in solving a different, novel problem mastering a different activity. This lifelong process of learning by shifting the focal points to newer areas or domains should continue throughout one's lifespan, to yield the full benefits of species-wide human inheritances. In fact, the capacity of continual growth of neural networks or creativity could be the most important feature that differentiates human beings from machines or typical computers.

\subsection{Understanding Focus on Concepts/Details and Explicit/Implicit Learning}

As we have highlighted above, learning abstract concepts is a higher-order learning process associated with enhancing human consciousness (see sections 2.4 and 3.4 for definition). These abstract concepts can often be generalisations (Penfield and Milner, 1958) across multiple domains, and as a result, can be presented from multiple perspectives. In this way, by highlighting broader concepts, we can reach out to learners from diverse backgrounds. Consequently, being able to present an abstract concept in a generalised manner viewing from multiple domains is a very strong tool to be in possession by educators. In addition, abstract concepts learned are stored as semantic memories for a longer period compared to detailed, more specific procedures stored as episodic or autobiographical memory (Baars \& Gage, 2010; Tulving, 1972, 1985). Usually, only some conceptual parts of the episodic memories we absorb will be retained in the longer run as semantic memories. Consequently, in academic learning environment, which are explicit by nature, it is important that we highlight relatively a small number of high-level concepts/generalisations rather than a higher number more specific details. More specifically, in assessments, we need to test the learners' ability to understand and retain high-level concepts instead of specific details, which will be retained in memory for a very short period of time. In a related note, it has been observed that most of our learning is implicit (see section 2.3 for details). That is, we retain some knowledge unconsciously as a by product of a conscious input. We can infer here that if a learner is capable of retaining some knowledge unconsciously for a longer period, it is stored as a semantic memory. Consequently, in our assessments, it is important that we evaluate learners' implicit learning components as well. To assess, implicit learning components, one possible approach we can take would be to include open-ended questions and observe the accurate, relevant and useful inference they can make. Open-ended questions can perform a priming function to stimulate learner brains and access implicit memories. (Roediger \& McDermott, 1993) In other words, we will not be able to assess a learner's implicit learning component by asking associative recall or objective type questions with only one correct answer. Instead, we may test the learners' ability to make a comparative judgement on a more open-ended matter. Our assessments here can be recognition tests, rather than associative recall (Baars \& Gage, 2010). In this approach, we support constructivist theory of learning in which learners make meaning individually within themselves. By doing this, we make our assessment fairer and more valid as far as active and lasting learning has taken place. Further, gifted learners are observed to be highly capable in incidental learning (Eide \& Eide, 2004); hance we give them a fairer chance to demonstrate their learning when more open-ended questions are used.

\subsection{Understanding the Need for Getting Learner Attention and Motivating Learners}

In a teaching-learning process, getting the full attention of learners is of immense significance. As described by the phenomenon known as binocular-rivalry as a human limitation, a learner cannot pay his/her full attention to more than one thing at a time (Logothetis, 1998; Tong et al, 1998). A learner has to have a high level of motivation towards the task or area being learned in order to pay full attention. In some cases, learners can be motivated to learn a specific area or task if they are emotionally attached to it. In other words, emotions can play a significant role motivating learners to pay attention (Damasio, 2005; Goleman, 2005; Zull, 2002; Panksepp, 1998). We, as educators, have the responsibility of motivating learners on the subject matter so that they pay full attention. One general way of motivating learners during a teaching-learning process is to present high-level abstract concepts/generalisations instead of more specific details. Since high-level concepts often cross the boundaries of domains, we can engage more learners in the teaching-learning process, based on their preferred domain. Since high-level concepts represent inter-domain knowledge, they can be more useful in a wide range of day-to-day life applications. In addition, since these high-level concepts are usually stored as semantic memory, they last longer in learners' memory (Tulving, 1972, 1985). These lasting memories can further be linked to other concepts learned in future as well. Further, we, as educators, can provide exclusive time for learners to take notes, if required, as divided attention (Anderson et al, 2000; Fletcher et al, 1995) on listening and note-taking at the same time can hamper the level of attention and deep engagement, thus the level of understanding achieved. 


\section{Conclusion}

From the evidence emerging in the area of neuroscience (Baars \& Gage, 2010), we as educators can get a deeper understanding into our pedagogical concepts and practices (Watagodakumbura, 2013). These evidences help us to take necessary changes in our practices so that learners are provided with a better opportunity to evolve as human beings by actualising their species-wide, human potential (Maslow, 1968, 1993). That is, we can direct our learners towards their full potential enhancing creativity, wisdom and consciousness so that their biologically enabling multifaceted developments help them to be better decision makers in everyday-life situations, not merely developing a limited set of skills in a more specific career area. Wisdom is understood as an advanced form of creativity that crosses the boundaries of domains (Claxton, 2008). Consequently, a larger number of brain functional areas become more integrated and active in involvements of wisdom. Similarly, researchers have now understood that consciousness can be studied scientifically (Baars et al, 2003; Edelman, 1989, 1993, 2005, 2007; Edelman \& Tononi, 2001; Koch, 1996; Palmer, 1999; Tononi \& Edelman, 1998; Tulving, 2002) as the integration of highly differentiated information across a larger number of brain functional areas ( (Bulduzzi \& Tononi, 2008; Koch and Tononi, 2008; Tononi, 2008). Further, it is understood that a higher-level of consciousness relates to a higher level of human development in which the frontal lobe, the organ of civilisation (Fuster, 1997; Goldberg, 2001; Ingvar, 1985; Luria, 1966), plays a significant role. When human beings develop towards full potential, they become more empathic and content personalities (Dabrowski, 1970, 1972, 1977) devoid of psychological and mental disorders (Webb, 2005, 2008).

Most of our learning is implicit - unconsciously retain memory traces from conscious input (Berry and Dienes, 1993; Cleeremans, 1993). Individual learners make their subjective inferences based on their existing individual neural networks. Further, emotions are understood to support implicit learning significantly (Phelps and LeDoux, 2005; Panksepp, 1998). Gifted learners typically demonstrate overexcitabilities such as emotional, intellectual and imaginational (Dabrowski, 1970, 1972, 1977) and they implicitly engage in incidental learning (Eide \& Eide, 2004). However, most of our academic learning is explicit and a large number of assessments test associative learning. That is, in academic tests we are asked mostly to find exact answers through mostly memory recall even though most of the decisions we make in day to day life situations are not exact by nature; rather these decisions we make most of the times are adaptive by nature (Baars \& Gage, 2010). In general, machines and typical computers can be more effectively used for finding exact answers following routine procedures. In the presence of this conflicting situation, the challenge for us, the educators, is to be fairer in assessment that also includes a component to test implicit learning and the ability to make better adaptive decisions, rather than to test the ability to follow a routine procedure to get to a final, exact answer.

In this paper, we identify the need to highlight high-level or abstract concepts/generalisations in any teaching-learning environment or in learner assessment. The significance of highlighting abstract concepts are pointed out explicitly in Kolb's experiential learning cycle (Kolb, 1983; Zull, 2002) and somewhat indirectly in Bloom's taxonomy (Biggs, 2003; Entwistle, 1998) at a higher synthesis level. These high-level concepts, in general, are not specific to any particular application, rather they cross domain boundaries. Consequently, these concepts can be presented to learners in a manner that integrates domains and activates a number of brain functional areas. Integrating information from multiple brain regions and domain areas helps us to enhance consciousness and wisdom in learners. Further, when presented this way, learners become more motivated to engage in learning actively as the concepts learned are more useful in a general way to their careers as well as day to day life situations, rather than in a narrow and more specific way. When learners are motivated and engaged in learning, it makes a lasting impact in memory. In addition, there is evidence in neuroscience that high-level concepts are stored as semantic memory that lasts longer, (Tulving, 1972; 1985). This contrasts with the more specific details that are held for a relatively short period of time as episodic memory.

\section{References}

Anderson, N. D., Iidaka, T, Cabeza, R., Kapur, S., McIntosh, A. R., \& Craik, F. I. (2000). The effects of divided attention on encoding- and retrieval-related brain activity: A PET study of younger and older adults. Journal of cognitive neuroscience, 12(5), 775-792. http://dx.doi.org/10.1162/089892900562598

Armstrong, T. (2011). The Power of Neurodiversity: Unleashing the Advantages of Your Differently Wired Brain. Da Capo Lifelong Books.

Baars, B. J. (1988). A cognitive theory of consciousness. New York: Cambridge University Press. 
Baars, B. J. (2002). The conscious access hypothesis: Origins and recent evidence. Trends in Cognitive Sciences, 6(1), 47-52. http://dx.doi.org/10.1016/S1364-6613(00)01819-2

Baars, B. J., \& Gage, N. M. (2010). Cognition, Brain, and Consciousness - Introduction to Cognitive Neuroscience( $2^{\text {nd }}$ Ed.). Elsevier, MA: USA.

Baars, B. J., Banks, W. P., \& Newman, J. B. (2003). Essential sources in the scientific study of consciousness. Cambridge: MIT Press.

Baddeley, A. D., \& Hitch, G. J. (1974). Working memory. In G. A. Bower (Ed.), Recent advances in learning and motivation: Vol. 8 (pp. 47-90). New York: Academic Press. http://dx.doi.org/10.1016/s0079-7421(08)60452-1

Baddley, A. D. (2000). The episodic buffer: a new component of working memory? Trends in Cognitive Sciences, 4(11), 417-423. http://dx.doi.org/10.1016/S1364-6613(00)01538-2

Balduzzi, D., \& Tononi, G. (2008). Integrated Information in Discrete Dynamical Systems: Motivation and Theoretical Framework. PLoS Computational Biology, 4(6). http://dx.doi.org/10.1371/journal.pcbi.1000091

Banaji, M. R., \& Greenwald, A. G. (1995). Implict gender stereo-typing in judgements of fame. Journal of Personality and Social Psychology, 68(2), 181-198. http://dx.doi.org/10.1037/0022-3514.68.2.181

Baron-Cohen, S. (1995). Mindblindness: An essay on autism and theory of mind. Boston: MIT Press /Bradford Books.

Beale, R., \& T. Jackson. (1990). Neural Computing - An Introduction. Institute of Physics Publishing. http://dx.doi.org/10.1887/0852742622

Berry, D. C., \& Dienes, Z, (1993). Implicit learning: Theoretical and empirical issues. Erlbaum.

Biggs, J. (2003). Teaching for Quality Learning at University ( $2^{\text {nd }}$ ed.). Buckingham, Society for Research into Higher Education and Open University Press.

Bowers, K. S., Regehr, G., Balthazard, C., \& Parker, K. (1990). Intuition in the context of discovery. Cognitive Psychology, 22(1), 72-110. http://dx.doi.org/10.1016/0010-0285(90)90004-N

Chein, J. M., \& Schneider, W. (2005). Neuroimaging studies of practice-related change: fMRI and meta-analytic evidence of a domain-general control network for learning. Brain Research. Cognitive Brain Research, 25(3), 607-623. http://dx.doi.org/10.1016/j.cogbrainres.2005.08.013

Claxton, G. (2008). Wisdom: Advanced Creativity? In A. Craft, H. Gardner \& G. Claxton (Eds.), Creativity, Wisdom and Trusteeship: Exploring the Role of Education. Thousand Oaks, CA: Corwin Press.

Cleeremans, A. (1993). Mechanisms of implicit learning: Connectionist models of sequence learning. MIT Press.

Cohen, N. J., \& Squire, L. R. (1980). Preserved learning and retention of pattern-analysing skill in amnesia: Dissociation of knowing how and knowing that. Science, 210(4466), 207-210. http://dx.doi.org/10.1126/science.7414331

Cowan, N., Izawa, C., \& Ohta, N. (2005). Working-memory capacity limits in a theoretical context. Human learning and memory: Advances in theory and application. The $4^{\text {th }}$ Tsukuba International Conference on Memory. Mahwah: Lawrence Erlbaum Associates, Publishers, p.155. http://dx.doi.org/10.4324/9780203342398

Curran, T. (2001). Implicit learning revealed by the method of opposition. Trends in Cognitive Sciences, 5(12), 503-504. http://dx.doi.org/10.1016/S1364-6613(00)01791-5

Dabrowski, K. (1972). Psychoneuroses Is Not An Illness. London: Gryf Publications.

Dabrowski, K. (1977). Theory of Levels of Emotional Development (vol 1) - Multilevelness and Positive Disintegration. New York: Dabor Science Publications.

Dabrowski, K. (with Kawczak A. and Piechowski M. M.). (1970). Mental Growth through Positive Disintegration. London: Gryf Publications

Damasio, A. (2005). Descartes Error: Emotion, Reason, and the Human Brain. London: Penguin Books.

den Ouden, H. E., Friston, K. J., Daw, N. D., McIntosh, A. R., \& Stephan, K. E. (2009). A dual role for prediction error in associative learning. Cerebral Cortex, 19(5), 1175-1185. http://dx.doi.org/10.1093/cercor/bhn161

Diamond, M. C. (1996). The Brain...Use it or Lose It. New Horizons for Learning: School of Education, Johns Hopkins University. Retrieved from http://education.jhu.edu/newhorizons/Neurosciences/articles/

Diamond, M. C. (2001). Response of the Brain to Enrichment. New Horizons for Learning: School of Education, 
Johns Hopkins University. Retrieved from http://education.jhu.edu/newhorizons/Neurosciences/articles/

Dudai, Y. (2004). The neurobiology of consolidations, or how stable is the engram? Annual Review of Psychology, 55, 51-86. http://dx.doi.org/10.1146/annurev.psych.55.090902.142050

Edelman, G. M. (1989). The remembered present: A biological theory of consciousness. New York: Basic Books Inc.

Edelman, G. M. (1993). Neural Darwinism : Selection and re-entrant signalling in higher brain function. Neuron, 10(2), 115-125. http://dx.doi.org/10.1016/0896-6273(93)90304-A

Edelman, G. M. (2005). Wider than the Sky: The Phenomenal Gift of Consciousness. Yale University Press, New Haven.

Edelman, G. M. (2007). Second Nature: Brain Science and Human Knowledge. Yale University Press, New Haven.

Edelman, G. M., \& Mountcastle, V. B. (1978). The mindful brain: Cortical organisation and the group-selective theory of higher brain function. Oxford: MIT Press.

Edelman, G. M., \& Tononi, G. (2001). A universe of consciousness: How matter becomes imagination. New York: Basic Books Inc.

Eide, B., \& Eide, F. (2004). Brains on Fire: The Multimodality of Gifted Thinkers. New Horizons for Learning: School of Education, Johns Hopkins University. Retrieved from http://education.jhu.edu/PD/newhorizons/Neurosciences/articles/

Entwistle, N. J. (1998). Approaches to Learning and Forms of Understanding. In Teaching and Learning in Higher Education, ed. B. Dart and G. Boulton-Lewis, 72-101. Melbourne, Australia: Australian Council for Educational Research.

Fletcher, , P. C., Frith, C. D., Grasby, P. M., Shallice, T., Frackowiak, R. S., \& Dolan, R. J. (1995). Brain systems for encoding and retrieval of auditory-verbal memory. An in vivo study in humans. Brain, 118(Pt 2), 401-416. http://dx.doi.org/10.1093/brain/118.2.401

Friederici, A. D. (2002). Towards a neural basis of auditory sentence processing. Trends in Cognitive Sciences, 6, 78-84. http://dx.doi.org/10.1016/S1364-6613(00)01839-8

Frith, C. D., \& Frith, U. (1999). Interacting minds-a biological basis. Science, 286(5445), 1692-1695. http://dx.doi.org/10.1126/science.286.5445.1692

Fuster, J. M. (1997). Network memory. Trends in Neurosciences, 20(10), 451-459. http://dx.doi.org/10.1016/S0166-2236(97)01128-4

Gardner, H. (2006). Multiple Intelligences: New Horizons. New York: Basic Books.

Geschwind, N. (1979). Specialisations of the human brain. Scientific American, 241(3), 180-199. http://dx.doi.org/10.1038/scientificamerican0979-180

Goldberg, E. (2001). The executive brain: Frontal lobes and the civilised mind (Vol xix). New York: Oxford University Press.

Goleman, D. (2005). Emotional Intelligence. New York: Bantam Books.

Hebb, D. O. (1949). The organisation of behaviour: A neuropsychological theory. Oxford: Wiley.

Hickok, G., \& Poeppel, D. (2007). Opinion- The cortical organisation of speech processing. Nature reviews Neuroscience, 8, 393-402. http://dx.doi.org/10.1038/nrn2113

Hobson, J. A., \& Stickgold, R. (1995). Sleep. Sleep the beloved teacher? Current biology, 5(1), 35-36. http://dx.doi.org/10.1016/S0960-9822(95)00011-X

Huttenlocher, P. R. (1994). Synaptogenesis, synapse elimination, and neural plasticity in human cerebral cortex: Threats to optimal development. In C. A. Nelson (Ed.), The minnesota symposia on child psychology, Vol. 27 (pp. 35-54). Hillsdale: Lawrence Erlbaum Associates.

Huttenlocher, P. R., De Courten, C., Garey, L. J., \& Van der Loos, H. (1982). Synaptic development in human cerebral cortex. International journal of Neurology, 16(17), 144-154.

Ingvar, D. H. (1985). Memory of the future: An essay on the temporal organisation of conscious awareness. Human Neurobiology, 4(3), 127-136.

James, W. (1890). The principles of psychology (Vol. I). New York: Henry Holt and Co, Inc. 
http://dx.doi.org/10.1037/11059-000

Knowlton, B. J., Mangels, J. A., \& Squire, L. R. (1996). A neostriatal habit learning system in humans. Science, 273(5280), 1399-1402. http://dx.doi.org/10.1126/science.273.5280.1399

Koch, C. (1996). A neural correlates of consciousness? Current Biology, 6(5), 492. http://dx.doi.org/10.1016/S0960-9822(02)00519-5

Koch, C., \& Tononi, G. (2008). Can Machines be Conscious? IEEE Spectrum, 45(6), 55-59. http://dx.doi.org/10.1109/MSPEC.2008.4531463

Kolb, D. (1983). Experiential Learning: Experience as the Source of Learning and Development. Upper Saddle River, NJ: Prentice Hall.

Kuhn, T. S. (1962). The structure of scientific revolutions. Chicago: The University of Chicago Press.

Langer, E. J., \& Imber, L. G. (1979). When practice makes imperfect: Debilitating effects of overlearning. Journal of Personality and Social Psychology, 37(11), 2014-2024. http://dx.doi.org/10.1037/0022-3514.37.11.2014

LeDoux, J. E. (1996). The emotional brain. New York: Simon \&Schuster.

Lees, G. V., Jones, E. G., \& Kandel, E. R. (2000). Expressive genes record memories. Neurobiology of Disease, 7(5), 533-536. http://dx.doi.org/10.1006/nbdi.2000.0348

Logothetis, N. K. (1998). Single units and conscious vision. Philosophical Transactions of the Royal Society of London. Series B, Biological Sciences, 353(1377), 1801-1818. http://dx.doi.org/10.1098/rstb.1998.0333

Luria, A. R. (1966). Higher cortical functions in man (translated by Haigh). London: Tavistock.

Luria, A. R. (1976). The neuropsychology of memory (translated by Haigh). Oxford: V. H. Winston \& Sons.

MacLean, P. D. (1967). The brain in relation to empathy and medical education. The journal of nervous and Mental Disease, 144(5), 374-382. http://dx.doi.org/10.1097/00005053-196705000-00005

Maslow, A. (1968). Toward a Psychology of Being. New York: Van Nostrand Reinhold.

Maslow, A. (1993). Farther Reaches of Human Nature. New York, N.Y., U.S.A.: Arkana.

McGaugh, J. L. (2000). Memory - A century of consolidation. Science, 287(5451), 248-251. http://dx.doi.org/10.1126/science.287.5451.248

Metcalfe, J. (1986). Feeling of knowing in memory and problem solving. Journal of Experimental Psychology. Learning, Memory, and Cognition, 12(2), 288-294. http://dx.doi.org/10.1037/0278-7393.12.2.288

Nauta, W. J. (1972). Neural association of the frontal cortex. Acta Neurobiologiae Experimentalis (Wars), 32(2), $125-140$.

Palmer, S. E. (1999). Colour, consciousness, and isomorphism constraint. Discussion 944-989. The behavioural and Brain Sciences, 22(6), 923-943. http://dx.doi.org/10.1017/S0140525X99002216

Panksepp, J. (1998). Affective neuroscience: The foundations of human and animal emotions. New York: Oxford University Press.

Paul, R., \& L. Elder. (2000). Critical Thinking - Tools for Taking Charge of Your Learning and Your Life. Pearson Education.

Penfield, W., \& Milner, B. (1958). Memory deficit produced by bilateral lesions in the hippocampal zone. AMA $\begin{array}{lllll}\text { Archives of Neurology and } & \text { Psychiatry, } & 79(5), & \text { 475-497. }\end{array}$ http://dx.doi.org/10.1001/archneurpsyc.1958.02340050003001

Peretz, I., \& Zatorre, R. J. (2005). Brain organisation for music processing. Annual Review of Psychology, 56, 89-114. http://dx.doi.org/10.1146/annurev.psych.56.091103.070225

Phelps, E. A., \& LeDoux, J. E. (2005). Contributions of the amygdale to emotion processing: From animal models to human behaviour. Neuron, 48(2), 175-187. http://dx.doi.org/10.1016/j.neuron.2005.09.025

Raaijmakers, J. G., \& Shiffrin, R. M. (1992). Models for recall and recognition. Annual Review of Psychology, 43, 205-234. http://dx.doi.org/10.1146/annurev.ps.43.020192.001225

Roediger, H. L., \& McDermott, K. B. (1993). Implicit memory in normal human subjects. Handbook Neuropsychology, 8, 63-131.

Rozin, P. (1976). The evolution of intelligence and access to the cognitive unconscious. Progress in Psychobiology 
and Physiological Psychology, 6, 245-280.

Ryle, G. (1949). The concept of mind. London: Hutchinson.

Schneider, W. (2009). Automaticity and consciousness. Elsevier Encyclopaedia of Consciousness. In W. Banks (Ed.), Encyclopaedia of Consciousness ( $1^{\text {st }}$ ed)(pp. 83-92). Amsterdam: Academic Press. http://dx.doi.org/10.1016/B978-012373873-8.00009-8

Scholz, J., Klein, M. C., Behrens, T. E. J., \& Johansen-Berg, H. (2009). Training induces changes in white matter architecture. Nature Neuroscience, 12, 1370-1371. http://dx.doi.org/10.1038/nn.2412

Seitz, A., \& Watanabe, T. (2005). A unified model for perceptual learning. Trends in Cognitive Science, 9(7), 329-334. http://dx.doi.org/10.1016/j.tics.2005.05.010

Shaw, P., Greenstein, D., \& Lerch, J. et al. (2006). Intellectual ability and cortical development in children and adolescent s. Nature, 440(7084), 676-679. http://dx.doi.org/10.1038/nature04513

Shiffrin, R. M., \& Schneider, W. (1977). Controlled and automatic human information processing: II. Perceptual learning, automatic attending and a general theory. Psychological Review, 84(2), 127. http://dx.doi.org/10.1037/0033-295X.84.2.127

Silverman, L. K. (2002). Upside-Down Brilliance: The Visual-Spatial Learner. Denver: DeLeon Publishing.

Silverman, L.K. (1998). Personality and Learning Styles of Gifted Children. In Excellence In Educating Gifted \& Talented Learners ( $3^{\text {rd }}$ ed), ed. Van Tassel - Baska, Denver, Colorado, USA: Love Publishing Company.

Squire, L. R. (2004). Memory systems of the brain: A brief history and current perspective. Neurobiology of Learning and Memory, 82, 171-177. http://dx.doi.org/10.1016/j.nlm.2004.06.005

Squire, L. R. (2009). Memory and brain systems: 1969-2009. Journal of Neuroscience, 29(41), 12711-12716. http://dx.doi.org/10.1523/JNEUROSCI.3575-09.2009

Sylwester, R. (1998). The Downshifting Dilemma: A Commentary and Proposal. New Horizons for Learning: School of Education, Johns Hopkins University. Retrieved from http://education.jhu.edu/newhorizons/Neurosciences/articles/

Tong, F., Nakayama, K., Vaughan, J. T., \& Kanwisher, N. (1998). Binocular rivalry and visual awareness in human extrastriate cortex. Neuron, 21(4), 753-759. http://dx.doi.org/10.1016/S0896-6273(00)80592-9

Tononi, G. (2008). Consciousness as Integrated Information: A Provisional Manifesto. Biological Bulletin, 215(3), 216-242. http://dx.doi.org/10.2307/25470707

Tulving, E. (1972). Episodic and semantic memory. In E. Tulving, W. Donaldson \& G. H. Bower (Eds.), Organisation of memory (pp. 381-403). New York: Academic Press.

Tulving, E. (1985). Elements of Episodic Memory. New York: Oxford University Press.

Unterrainer, J. M., \& Owen, A. M. (2006). Planning and problem solving: From neuropsychology to functional $\begin{array}{lllll}\text { neuroimaging. Journal of Physiology } & \text { 308-317. }\end{array}$ http://dx.doi.org/10.1016/j.jphysparis.2006.03.014

Watagodakumbura, C. (2013b). Education from a Deeper and Multidisciplinary Perspective - To a Sustainable Development of a Neurodiverse Society - A Futuristic View. USA: Xlibris.

Webb, J. T. (2008). Dabrowski's Theory and Existential Depression in Gifted Children and Adults. Paper presented at the Eighth International Congress of the Institute for Positive Disintegration in Human Development, August 7-9, Alberta, Canada.

Webb, J.T., Amend E. R., Webb N.E., Goerss J., Beljan P., \& Olenchak F.R. (2005). Misdiagnosis and Dual Diagnoses of Gifted Children and Adults: ADHD, Bipolar, Ocd, Asperger's, Depression, and Other Disorders. USA: Great Potential Press.

Yzerbyt, V. Y., Lories, G., \& Dardenne, B. (Eds.) (1998). Metacognition: Cognitive and social dimensions. Thousand Oaks: Sage Publications. http://dx.doi.org/10.4135/9781446279212

Zull, J. E. (2002). The Art of Changing the Brain: Enriching the Practice of Teaching by Exploring the Biology of Learning. Stylus Publishing. 